\title{
THE PROPERTIES AND HYDRATION OF PORTLAND CEMENT CONTAINING CALCIUM SULFOALUMINATE CEMENT
}

\author{
WEIFENG LI*, JIN YU*, "SUHUA MA*, YUEYANG HU*, DASHUN GE*, XIAODONG SHEN*, ** \\ *College of Materials Science and Engineering, Nanjing Tech University, Nanjing 210009, China \\ **State Key Laboratory of Materials-Oriented Chemical Engineering, China \\ ${ }^{\#}$ E-mail: msh@njtech.edu.cn
}

Submitted May 6, 2018; accepted July 17, 2018

\begin{abstract}
Keywords: Portland cement, Calcium sulfoaluminate cement, Physical properties, Hydration kinetics
Calcium sulfoaluminate (CSA) cement has some attractive qualities, such as rapid setting, high early strength, and microexpansion. It was commonly used to improve properties of Portland cement (PC). In this paper, the investigated results show that the setting times are notably reduced as the CSA cement content is increased. The compressive strength is slightly lower for the PC-CSA blends containing less than $10 \%$ CSA cement, but notably lower for the PC-CSA blend containing $20 \%$ CSA cement when compared to PC. High amounts of CSA cement significantly delay the hydration of alite, thereby increasing the porosity. Furthermore, the addition of CSA cement changes the ettringite morphology.
\end{abstract}

\section{INTRODUCTION}

Given the increasing requirements for Portland cement (PC), a series of problems have gradually emerged during the manufacturing of $\mathrm{PC}$, such as environmental pollution and high energy consumption. Compared to PC clinker, calcium sulfoaluminate (CSA) clinker requires less limestone and energy [1, 2]. Additionally, the burning temperature of CSA clinker $\left(1250-1350^{\circ} \mathrm{C}\right)$ is significantly lower than that of PC clinker (approx. $1450^{\circ} \mathrm{C}$ ) [3]. CSA cement has some attractive properties, such as rapid setting, high early strength, and micro-expansion [4]. To save energy, reduce the cement industry's emissions, and improve some of the properties of PC-based concrete, the majority of research has focused on the high addition of CSA cement on the properties and hydration of blends made of ordinary Portland cement (OPC) and CSA cement. For example, a direct encapsulation of low-level radioactive waste was made of a blend of $30 \%$ OPC and $70 \%$ CSA cement and increased the waste load by $56 \%$ [5]. Péra and Ambroise [6] prepared a concrete with high early strength of $40 \mathrm{MPa}$ at $6 \mathrm{~h}$ and higher than $55 \mathrm{MPa}$ after $24 \mathrm{~h}$ by mixing $80 \%$ CSA cement and $20 \%$ OPC. The CSA clinker has been shown to be mainly responsible for the early mechanical properties, whereas OPC plays an important role at later ages in blends with $\mathrm{OPC} /$ CSA weight ratios of $6: 3,7: 3$, and 8:3 [8]. 10\% CSA cement did not affect the hydration mechanism of alite but did control the aluminate dissolution in OPC [9]. Chaunsali and Mondal [7] investigated the expansion of OPC containing different amounts of CSA cement and proposed that increasing the CSA cement content increased the extent of expansion, and the samples containing the highest CSA cement content tested (30\% by mass) exhibited excessive expansion, which led to cracking because ettringite supersaturation gave rise to crystallisation stress.

For more than ten years, we have been working on an Alite-ye'elimite system clinker. The Alite-ye'elimite clinker was synthesised by chemically introducing small amount of ye'elimite into Portland clinker during calcination [12-13]. We concluded that small amount of ye'elimite introduced could significantly improve early compressive strengths of Portland clinker, especially at 1 day. Consequently, we wanted to investigate whether small amount of CSA cement added physically could enhance the early compressive strength of Portland cement. Then, the effects of the small amount of CSA cement on the hydration of Portland cement have been studied.

\section{EXPERIMENTAL}

Raw materials

All of the experiments were conducted using Portland cement (PC) and commercial CSA cement. The chemical and mineralogical compositions of the two cements are given in Table 1 as determined by X-ray fluorescence (XRF) and quantitative X-ray diffraction (QXRD), respectively. 
Table 1. Chemical analysis of materials by XRF and the main phase composition of the materials by QXRD (O Orthorhombic, $\mathrm{C}-\mathrm{Cubic}$ ).

\begin{tabular}{|c|c|c|c|c|c|}
\hline $\begin{array}{l}\text { Chemical } \\
\text { analysis }\end{array}$ & PC & $\begin{array}{c}\text { CSA } \\
\text { cement }\end{array}$ & $\begin{array}{l}\text { Mineralogical } \\
\text { composition }\end{array}$ & $\mathrm{PC}$ & $\begin{array}{c}\text { CSA } \\
\text { cement }\end{array}$ \\
\hline & \multicolumn{2}{|c|}{$(\%)$} & & \multicolumn{2}{|c|}{$(\%)$} \\
\hline Loss & 3.24 & 3.63 & $\mathrm{C}_{3} \mathrm{~S}$ & 51.2 & - \\
\hline $\mathrm{CaO}$ & 65.06 & 42.80 & $\mathrm{C}_{2} \mathrm{~S}$ & 13.4 & 19.1 \\
\hline $\mathrm{MgO}$ & 0.71 & 2.94 & $\mathrm{C}_{4} \mathrm{~A}_{3} \$(\mathrm{O})$ & - & 23.0 \\
\hline $\mathrm{SO}_{3}$ & 2.63 & 18.38 & $\mathrm{C}_{4} \mathrm{~A}_{3} \$_{2}(\mathrm{C})$ & - & 23.5 \\
\hline $\mathrm{Al}_{2} \mathrm{O}_{3}$ & 4.25 & 21.06 & Anhydrite & 0.4 & 15.3 \\
\hline $\mathrm{K}_{2} \mathrm{O}$ & 0.69 & 0.46 & $\mathrm{C}_{3} \mathrm{~A}$ & 6.1 & - \\
\hline $\mathrm{Fe}_{2} \mathrm{O}_{3}$ & 3.01 & 1.48 & Ferrite & 7.5 & - \\
\hline $\mathrm{SiO}_{2}$ & 19.62 & 12.66 & $\mathrm{C}_{12} \mathrm{~A}_{7}$ & - & 2.5 \\
\hline $\mathrm{Na}_{2} \mathrm{O}$ & 0.01 & 0.05 & Calcite & 3.8 & 4.1 \\
\hline \multirow[t]{2}{*}{$\mathrm{TiO}_{2}$} & 0.23 & 0.76 & Dolomite & - & 3.9 \\
\hline & & & Perovskite & - & 3.0 \\
\hline
\end{tabular}

\section{Preparation of the samples}

The dosages of CSA cement are 1, 3, 5, 10 and $20 \%$ by weight of PC. First, the PC and CSA cement were weighed separately, and then, they were mixed for 1 day in a shaker-mixer.

The paste was prepared by stirring the mixture of a blend and water for 2 min with a speed of $500 \mathrm{rpm}$. The ratio of water to the blend was 0.5 . The fresh paste was poured into plastic bottles, and then, the bottles were sealed and stored in a curing box with $98 \%$ humidity at $20^{\circ} \mathrm{C}$. After $30 \mathrm{~min}, 1 \mathrm{~h}, 6 \mathrm{~h}, 1$ day, 3 days and 28 days, the hardened pastes were removed from the plastic bottles and cut into small pieces. Then, hydration was stopped by submerging the small pieces in ethanol for 1 day. After that, the pieces were dried in an oven at $40^{\circ} \mathrm{C}$ for 1 day. Some of the dried pieces were ground, and all the particles were passed through an $80-\mu \mathrm{m}$ sieve for X-ray diffraction (XRD) and thermogravimetric (TG) experiments. The other pieces were retained for scanning electron microscopy (SEM) and mercury intrusion porosimetry (MIP) experiments.

\section{Methods \\ Amounts of water required for normal consistency and setting time}

The amounts of required water for a normal consistency and setting time were determined with a Vicat apparatus in accordance with the Chinese National Standard (GB/T1346-2011).

\section{Compressive strength}

The compressive strength was measured according to the Chinese National Standard (GB/T17671-1999). Mortar bars were cast at $20^{\circ} \mathrm{C}$ and $98 \%$ relative humidity using a water-to-cement ratio of 0.5 and a sand-to-cement ratio of 3 . The bars were removed from the mould after $24 \mathrm{~h}$ and placed into a curing box at $98 \%$ relative humidity and $20^{\circ} \mathrm{C}$. The mortar bars were tested at 1,3 , and 28 days using an AEC-201 Automatic cement strength tester with a maximum load of $200 \mathrm{kN}$. The loading rate of the machine was $2.4 \pm 0.2 \mathrm{kN} \cdot \mathrm{s}^{-1}$.

\section{Hydration heat flow}

The hydration heat release of the blended cement was determined by a conduction calorimeter (Thermometric TAM Air). The ratio of water to blended cement was 0.5 . First, $4 \pm 0.01 \mathrm{~g}$ of blended cement was weighed and poured into a plastic ampule. Then, an appropriate amount of water was suctioned by an admix ampoule and weighed according to the desired ratio of water to the blended cement. After that, the plastic ampule was sealed with the admix ampoule. Subsequently, the data was collected after the sealed plastic ampule was placed into the calorimeter. Finally, water was injected into the plastic ampule and mixed with the admix ampoule for $2 \mathrm{~min}$ when thermal equilibration of the conduction calorimeter was achieved.

\section{$X$-ray diffraction (XRD) analysis}

The XRD experiments were performed with a PANalytical X'Pert Pro MPD diffractometer using $\mathrm{Cu}$ Ka radiation $(\lambda=1.54 \AA$ ) working in a Bragg-Brentano geometry with a $2 \theta$-range of $5-65^{\circ}$. Qualitative analysis was performed using the Search Match software.

A combination of XRD and Rietveld refinement was used for the phase quantification. The Rietveld quantitative analysis was performed with GSAS [14] and EXPGUI [15]. The refinements were performed based on the structure models shown in Table 2. The profile was fitted using pseudo-Voigt functions. The background was fitted graphically with the shifted Chebyshev polynomial using 10 coefficients (more than 20 points were picked). The fitted parameters included phase fractions, lattice parameters and profile parameters.

Table 2. Powder mixture proportions (volume) and designations.

\begin{tabular}{ccc}
\hline Designation & $\%$ PC & \% CSA cement \\
\hline $\mathrm{P}$ & 100 & 0 \\
$1 \%$ & 100 & 1 \\
$3 \%$ & 100 & 3 \\
$5 \%$ & 100 & 5 \\
$10 \%$ & 100 & 10 \\
$20 \%$ & 100 & 20 \\
$\mathrm{~S}$ & 0 & 100 \\
\hline
\end{tabular}

\section{Thermogravimetric (TG) analysis}

The TG experiments were performed on a Mettler Toledo TGA/DSC1 STAR ${ }^{\mathrm{e}}$ instrument. Approximately $30 \mathrm{mg}$ of the sample was placed in an alumina crucible and heated up to $1000^{\circ} \mathrm{C}$ at a rate of $10^{\circ} \mathrm{C} \cdot \mathrm{min}^{-1}$ under an $\mathrm{N}_{2}$ atmosphere. 
Scanning electron microscopy (SEM) analysis

A JSM-7600F SEM was used to observe the morphologies of the hydration products. For this analysis, small pieces were coated with gold in advance and examined at $15 \mathrm{kV}$.

\section{Mercury intrusion porosimetry (MIP) analysis}

This measurement was performed on a Quanta chrome PoreMaster GT60 MIP. This instrument has high pressure in the range of 20 to $20000 \mathrm{psi}$ and low pressure in the range of 1.1 to $20 \mathrm{psi}$ and can be used to measure pore sizes ranging from 0.0035 to $400 \mu \mathrm{m}$. The pore radii were calculated according to the Washburn equation, i.e., $r=-2 \gamma \cos \theta / P$, where $r$ is the pore entry radius in which mercury intrudes, $\gamma$ is the surface tension, and $\theta$ and $P$ are the contact angle of mercury with the solid and the applied pressure, respectively. The contact angle was $140^{\circ}$, and $\gamma$ was $0.48 \mathrm{~N} \cdot \mathrm{m}^{-1}$.

\section{RESULTS AND DISCUSSION}

\section{Setting times and quantities of required water for normal consistency}

The addition of small quantities of CSA cement decreased the quantities of required water for a normal consistency (Figure 1). At CSA cement contents exceeding $3 \%$ by weight of the $\mathrm{PC}$, the quantities of required water increased significantly as the amount of CSA cement increased.

The setting times (Figure 1) depended on the dosages of the CSA cement. The addition of CSA cement substantially affected the setting times. The setting times decreased until a dosage of $20 \%$ CSA cement. The setting times hardly decreased with dosages higher than $20 \%$ CSA cement. In addition, the duration of setting was equal to whatever the CSA dosage was. At the do-

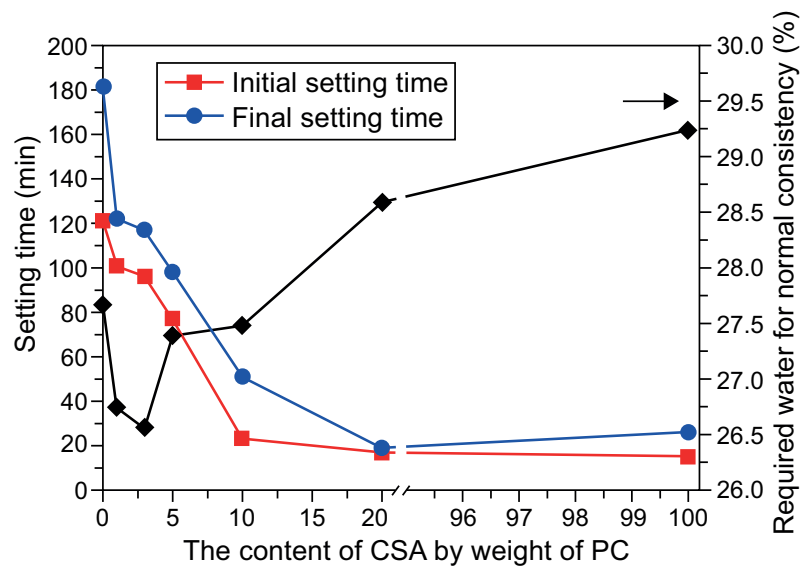

Figure 1. Setting times and quantities y of the required water of the blended cements. sage of $20 \%$ CSA cement, the duration of setting was close to zero. Therefore, CSA cement has frequently been used as an accelerating agent to promote the setting and hardening of PC used to repair various civil engineering constructions. However, higher dosages of CSA cement exerted no obvious effects on the setting times.

\section{Compressive strengths of the mortars}

Figure 2 depicts the compressive strengths of the blends mortars. Compared to the PC mortars, the compressive strengths of pure CSA cement mortars were higher at $1 \mathrm{~d}$ and $3 \mathrm{~d}$ because of the rapid hydration of ye'elimite, as previously reported by Pelletier et al. [8]. At $28 \mathrm{~d}$, the pure CSA cement mortars exhibited decreased compressive strengths in comparison to the pure PC mortars. In addition, the pure CSA cement mortars exhibited relatively low rates of increase. In this experiment, although the pure CSA cement has high early strength, adding it to the PC did not enhance the strengths of the blends. Compared to the pure PC mortars, the compressive strengths of the blended mortars decreased at any age. In particular, the compressive strengths of the mortars made of the blend containing $20 \%$ CSA cement were decreased substantially. This behaviour is in good agreement with the results reported by Yang Lin [27]. But, it is very interesting that the early compressive strengths (e.g., at $1 \mathrm{~d}$ and $3 \mathrm{~d}$ ) of the PC could be enhanced if a small amount of ye'elimite was incorporated chemically into the PC clinker during the burning process [12]. These results claimed that the physical addition of CSA cement did not improve the early strength and late strength of the PC.

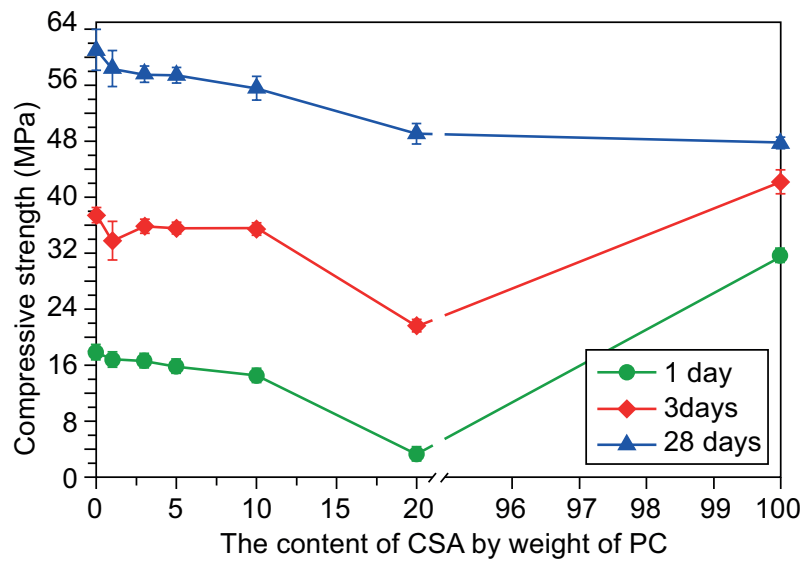

Figure 2. Compressive strengths of the cement mortars with different amounts of the CSA cement.

\section{Hydration kinetics of the blends}

The heat flow curves of the different blends are given in Figure 3. The PC exhibited a typical heat flow curve (Figure 3a) containing two peaks. The initial peak 
was assigned to a combination of exothermic wetting and the formation of a gelatinous coating and AFt-phase rods [9, 28-30], followed by an induction period until approximately 3 hours of hydration (Figure $3 b$ ). After the induction period, a maximum exothermic peak appeared at approximately 13 hours. The second peak corresponded to the hydration of $\mathrm{C}_{3} \mathrm{~S}$. The $\mathrm{PC}$ showed a shoulder to the right of the second peak at approximately 17 hours. The shoulder was associated with the renewed formation of AFt [9, 28, 31], and Rahhal [32] reported that this peak relates to the transformation of AFt to monosulfoaluminate (AFm).

The heat flow curve of the pure CSA cement contained three main exothermic peaks (Figures 3a, b). However, the positions of the peaks differed from those of the PC, except for the first one. For the CSA cement, the initial peak appeared at $30 \mathrm{~min}$ and was attributed to a combination of wetting and AFt formation. Compared to the PC, the CSA cement exhibited a higher initial peak due to rapid hydration of ye'elimite (Figure $3 b$ ). In addition, the induction period of the CSA cement was shorter, which is in agreement with the setting times. After the induction period, the second exothermic peak was observed at about $1.75 \mathrm{~h}$ corresponding to the induction period of the PC. The CSA cement showed a shoulder on the right of the second peak. At about $22 \mathrm{~h}$, the third peak presented in the heat flow curve of the CSA cement. As previously reported [33], hydration of the CSA cement involves a multi-stage acceleration-decelerationacceleration process. However, some anhydrites were retained for up to $1 \mathrm{~d}$ (Figure $4 \mathrm{~d}$ ). Therefore, these peaks were attributed to the formation of ettringite at different stages of hydration.

For the blends, their hydration kinetics were greatly different from that of the PC or CSA cement as the dosage of the CSA cement increased (Figure 3a, b). Compared to the PC, the exothermic heat flows were higher for the blends within $30 \mathrm{~min}$ due to the incorporation of ye'elimite. The blend containing $1 \%$ CSA cement presented a second exothermic peak that was similar

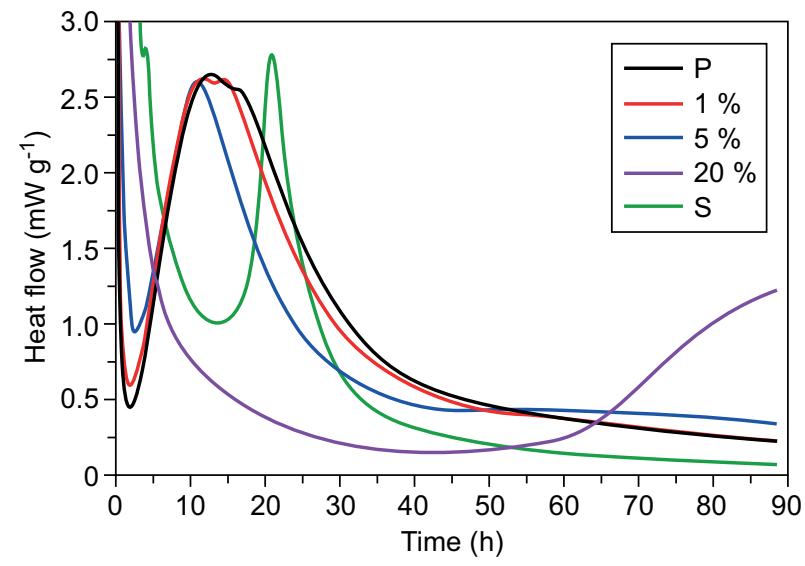

a) 0 to $88 \mathrm{~h}$ to that of the PC. But the shoulder on the right of the second peak was advanced for the blend containing $1 \%$ CSA cement. For the blend containing $5 \%$ CSA cement, no shoulder was observed in the curve of the heat flow. However, there seemed to be an exothermic peak at about $70 \mathrm{~h}$ for the blend containing $5 \% \mathrm{CSA}$ cement. The hydration kinetics of the blend containing $20 \%$ CSA changed obviously compared to those of the other blends. In addition to the initial peak, the blend containing $20 \%$ CSA cement exhibited the second exothermic peak within $3 \mathrm{~h}$, which was similar to the pure CSA cement. Small amounts of anhydrite were retained in the blend containing $20 \%$ CSA cement within $1 \mathrm{~h}$ of hydration, and no portlandite was noted (Figure 5a). Therefore, the second peak was caused by the renewed formation of ettringite. In addition, the heat release peak from the hydration of alite was present at about $90 \mathrm{~h}$, which was significantly delayed for the blend containing $20 \%$ CSA cement (Figure 3a).

\section{$\mathrm{XRD}$ analysis}

The XRD patterns for the blends hydrated for 30 min, 1 h, 6 h, 1 d, 3 d, and 28 d are shown in Figure 4. For the PC, the clinker phases, such as $\mathrm{C}_{3} \mathrm{~A}$, ferrite, $\mathrm{C}_{3} \mathrm{~S}$ and $\mathrm{C}_{2} \mathrm{~S}$, were consumed at different rates. Ettringite formed at $30 \mathrm{~min}$ of hydration due to the rapid reaction of the aluminate phase and gypsum (Figure 4a). Gypsum was no longer detectable after $1 \mathrm{~d}$ (Figures $4 \mathrm{~d}$, e, f). At $28 \mathrm{~d}$, some of the ettringite transformed to monocarboaluminate because of the absence of gypsum (Figure 4f). In addition, $\mathrm{C}_{3} \mathrm{~A}$ was almost depleted, whereas a small quantity of ferrite was retained because of its relatively slow hydration rate. Portlandite formed at $1 \mathrm{~d}$ (Figure 4d) via the hydration of $\mathrm{C}_{3} \mathrm{~S}$ at the early ages, and its content increased steadily with the hydration age. The other hydration product, i.e., $\mathrm{C}-\mathrm{S}-\mathrm{H}$, was not observed in the XRD patterns because of its poor crystallinity.

For the pure CSA cement, the hydration products differed from those of the PC. As shown in Table 1, the

Figure 3. Heat flow curves as a function of time for the different samples: a) 0 to $88 \mathrm{~h}, \mathrm{~b}$ ) 0 to $3 \mathrm{~h}$. 


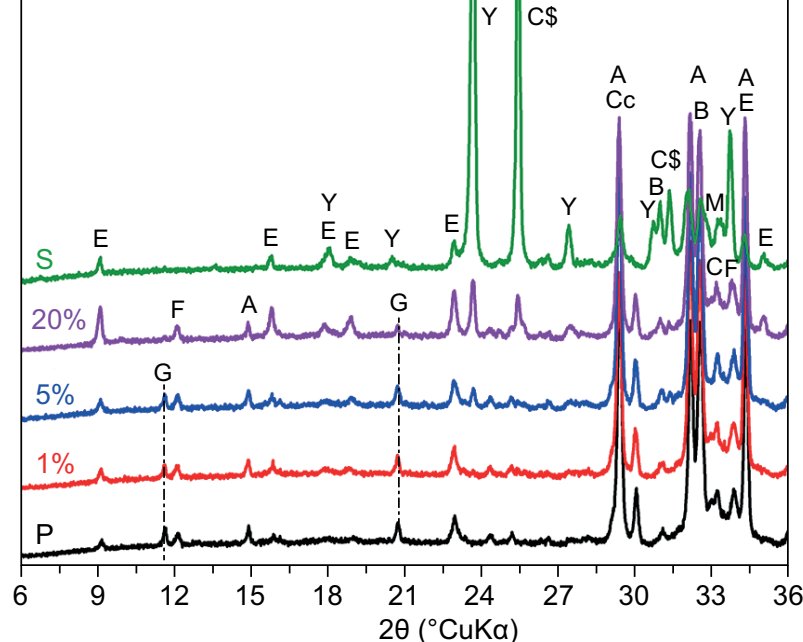

a) $30 \mathrm{~min}$

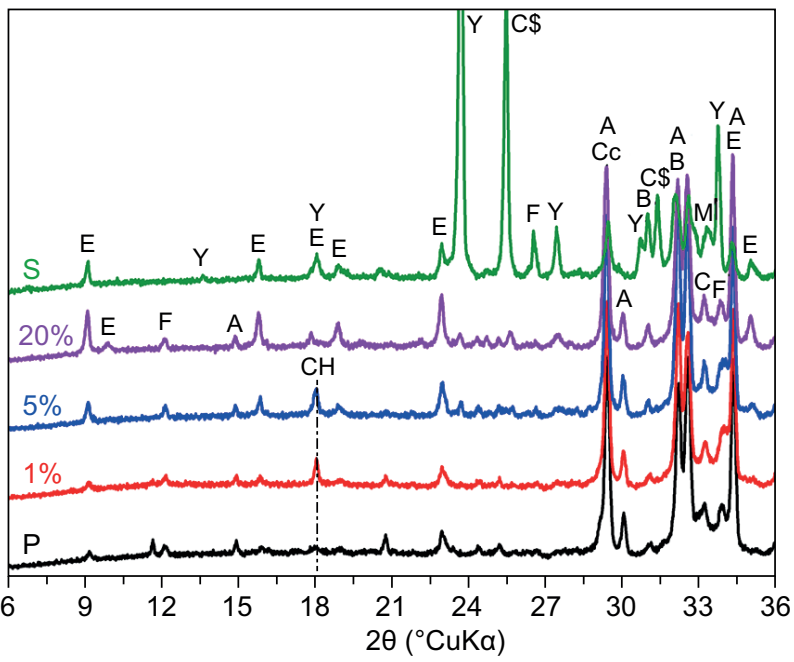

c) 6 hours

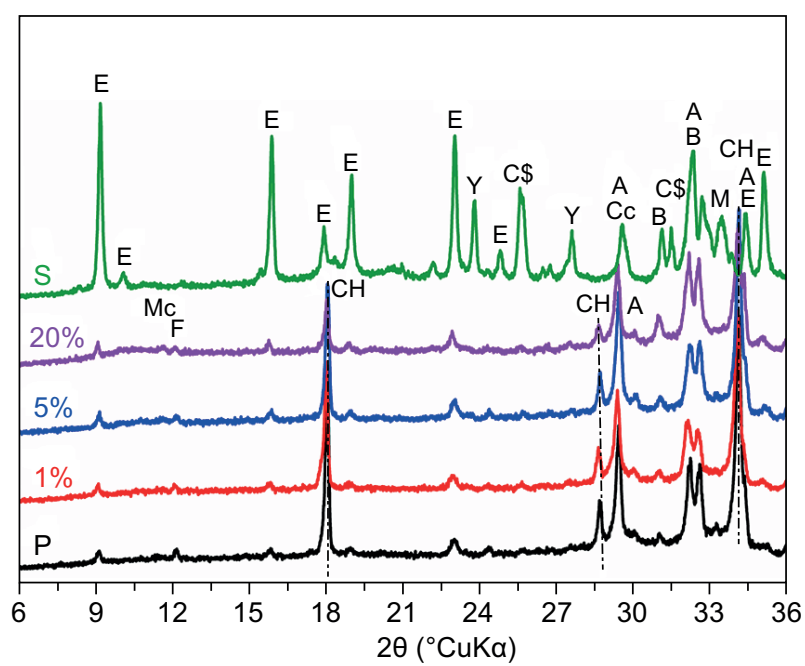

e) 3 days

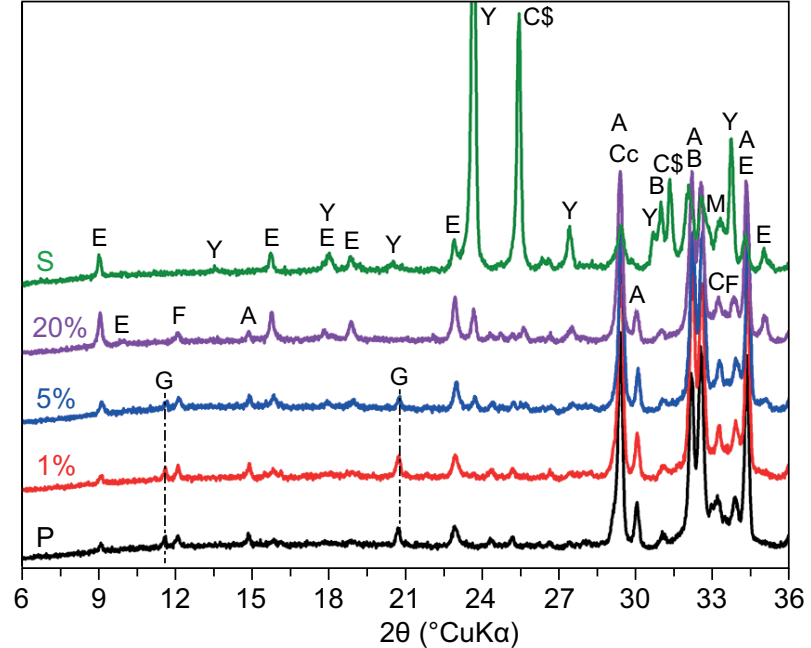

b) 1 hour

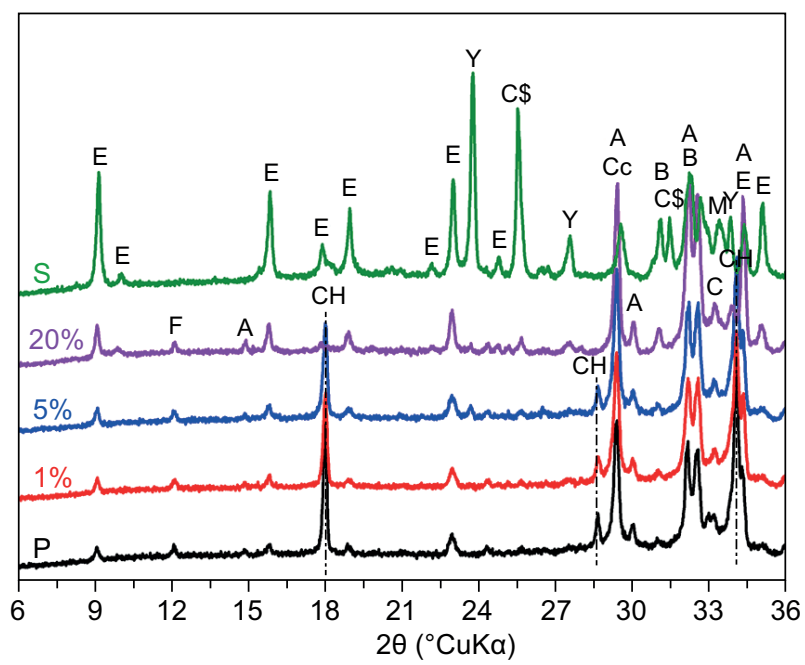

d) 1 day

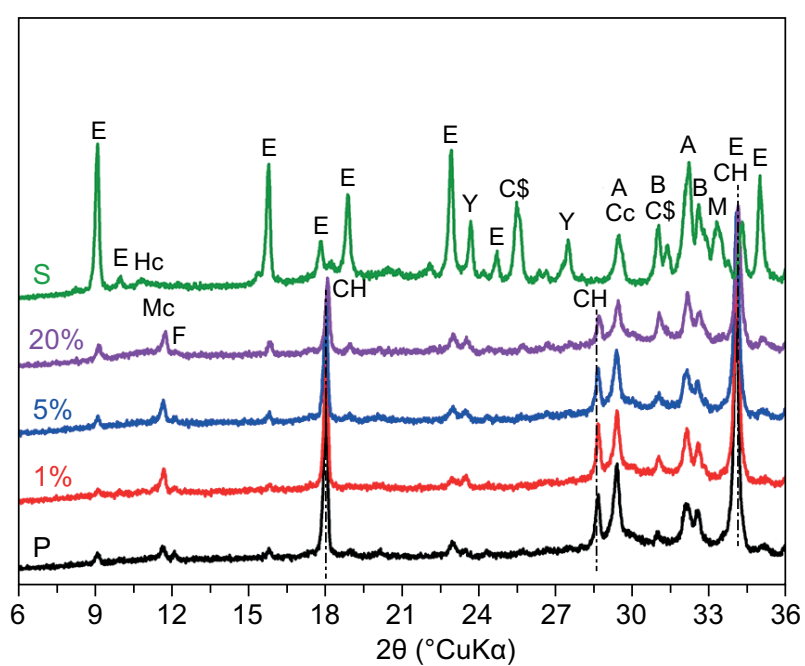

f) 28 days

Figure 4. XRD patterns of the different cements hydrated for 30 min, 1 h, 6 h, $1 \mathrm{~d}, 3 \mathrm{~d}$, and $28 \mathrm{~d}$ (E - Ettringite; Y - Ye'elimite; C\$ - Anhydrate; G - Gypsum; Cc - Calcite; CH - Portlandite; Ms: Monosulfoaluminate; Hc - Hemicarboaluminate; Mc - Monocarboaluminate; $\mathrm{C}$ - Aluminate phase; F - Ferrite phase; A - Alite; B - Belite. 
main phases were $\mathrm{C}_{2} \mathrm{~S}, \mathrm{C}_{4} \mathrm{~A}_{3} \$, \mathrm{C}_{12} \mathrm{~A}_{7}$, and anhydrate. The total amounts of $\mathrm{C}_{4} \mathrm{~A}_{3} \$$ and $\mathrm{C}_{12} \mathrm{~A}_{7}$ were much greater than that of $\mathrm{C}_{3} \mathrm{~A}$ in the PC. At the early ages, the contents of ettringite were higher in the CSA than those in the PC due to rapid hydration of ye'elimite (Figures $4 a, b, c)$, reaching a plateau within $30 \mathrm{~min}$ and remaining more or less constant until approximately $1 \mathrm{~d}$. At $1 \mathrm{~d}$, the contents of ettringite increased substantially in the CSA (Figures $4 \mathrm{~d}, \mathrm{e}, \mathrm{f}$ ). The diffraction peaks intensities of ye'eli-mite notably decreased. These results further indicated that the exothermic peak at about $20 \mathrm{~h}$ was attributed to the multiple hydration points of ye'elimite for the CSA cement. Simultaneously, the contents of sulphate decreased with the formation of ettringite. However, some anhydrite was retained up to $28 \mathrm{~d}$.

For the blended cements, the addition of CSA significantly accelerated the formation of ettringite at the early age, and the contents of ettringite increased with the CSA dosage at the same hydration age. It was very interesting that the contents of ettringite were higher for the blend with $20 \%$ CSA within $6 \mathrm{~h}$, compared to the pure CSA cement. S. Allevi et al. [35] reported that the increased soluble ettringite phase formation was detected with greater $\mathrm{C}_{4} \mathrm{~A}_{3} \$$ consumption in the first hours of the hydration of the CSA clinker in the presence of gypsum compared to anhydrite. Furthermore, the addition of CSA cement accelerated the consumption of gypsum. Gypsum nearly disappeared from the blend with $20 \%$ CSA cement at $1 \mathrm{~h}$, whereas some gypsum was retained in the PC (Figure 4b). Interestingly, the characteristic peak of portlandite appeared in the XRD patterns for the blends pastes with $1 \%$ and $5 \%$ CSA cement after hydration of $6 \mathrm{~h}$, but it did not appear in the $\mathrm{PC}$ paste and the blend paste containing $20 \% \mathrm{CSA}$. The characteristic peak of portlandite did not appear until $3 \mathrm{~d}$ for the blend paste with $20 \%$ CSA cement. At $28 \mathrm{~d}$, some monocarboaluminate formed in the blends pastes due to the presence of calcite.

\section{TGA}

The TG curves and corresponding derivative TG (DTG) curves are shown in Figure 5 for all the samples hydrated for $1 \mathrm{~h}, 1 \mathrm{~d}, 3 \mathrm{~d}$, and $28 \mathrm{~d}$. Based on the results of the XRD experiments, the endothermic peak at approximately $100^{\circ} \mathrm{C}$ can be attributed to the dehydration of ettringite/ and $\mathrm{C}-\mathrm{S}-\mathrm{H}$ for all the samples. The mass loss at approximately $100^{\circ} \mathrm{C}$ further showed that the addition of CSA cement promoted the formation of ettringite within $1 \mathrm{~h}$ (Figure 5a). The endothermic

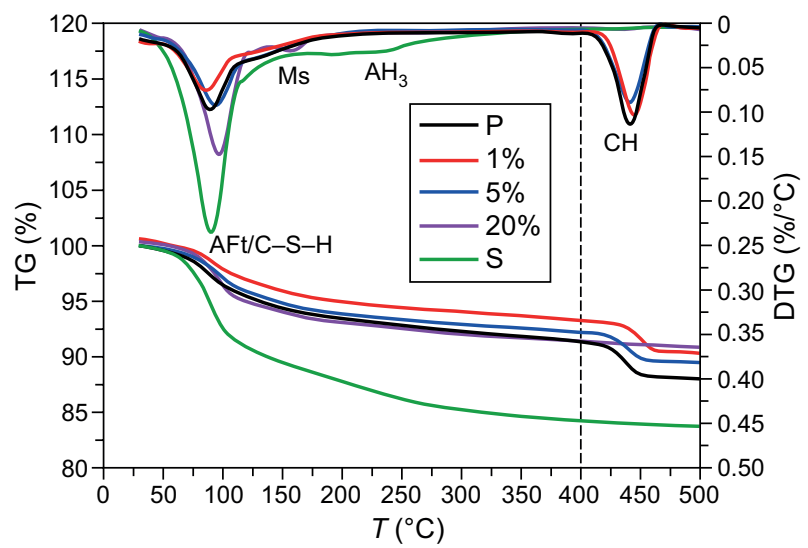

b) 1 day

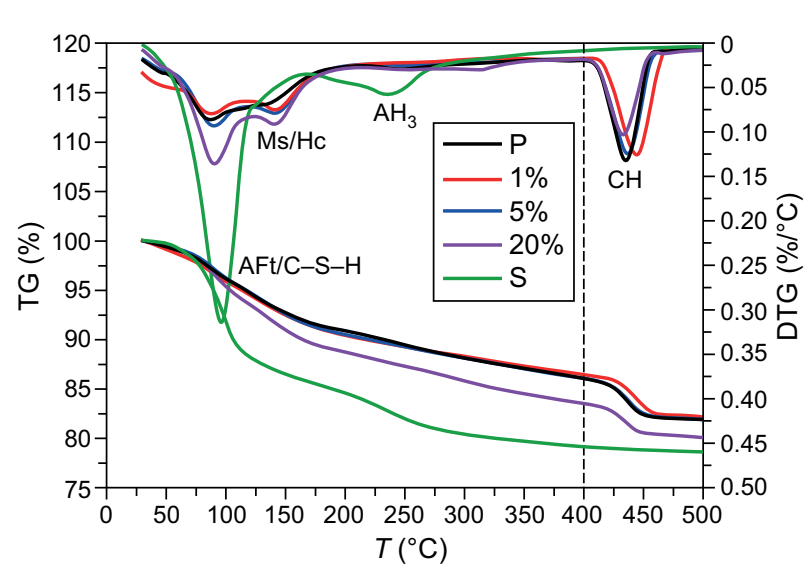

d) 28 days

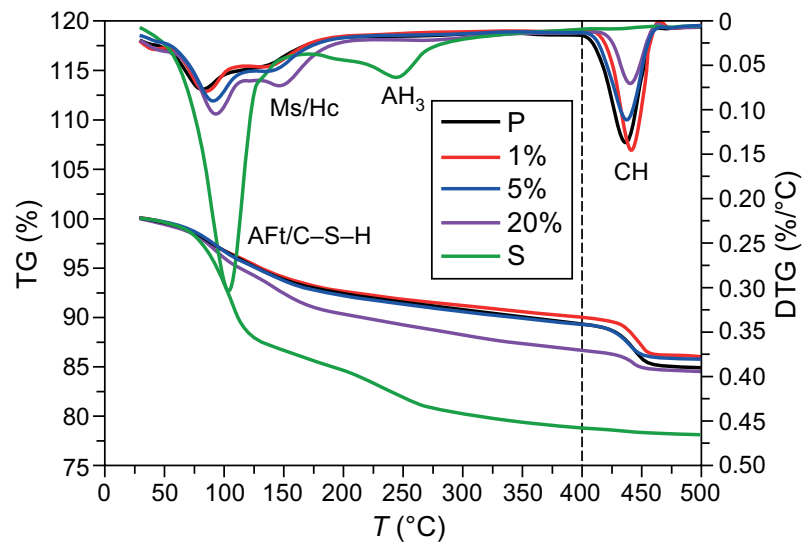

c) 3 days
Ettringite; Ms - Monosulfoaluminate;

Figure 5. The TG-DTG curves of the cement pastes at the different hydration ages (AFt - Ettringite; $\mathrm{M}$
$\mathrm{Hc}-$ Hemicarboaluminate; $\mathrm{Mc}-$ Monocarboaluminate; $\mathrm{CH}-$ Portlandite; $\mathrm{G}-\mathrm{Gypsum} ; \mathrm{AH}_{3}-\mathrm{Al}(\mathrm{OH})_{3}$. 
peak at $125^{\circ} \mathrm{C}$ corresponded to the dehydration of gypsum. Large amounts of gypsum were depleted in the blend with $20 \%$ CSA cement at $1 \mathrm{~h}$. The endothermic peak at approximately $250^{\circ} \mathrm{C}$ was ascribed to the dehydration of $\mathrm{Al}(\mathrm{OH})_{3}$ from the hydration reaction of $\mathrm{C}_{4} \mathrm{~A}_{3} \$$, whereas that at approximately $400^{\circ} \mathrm{C}$ resulted from the dehydration of portlandite. As the hydration age increased, the content of portlandite also increased significantly for the PC and blends with $1 \%$ and $5 \%$ CAS cement hydrated. No portlandite formed in the CSA cement because of the lack of alite. Additionally, no portlandite was observed in the blend with $20 \%$ CSA cement at $1 \mathrm{~d}$ also, demonstrating that the addition of CSA hindered its formation. However, a small amount of monocarboaluminate formed at $1 \mathrm{~d}$ in the blend with $20 \%$ CSA because of the presence of calcite and the absence of sulfates; this formation corresponded to the endothermic peak at approximately $150^{\circ} \mathrm{C}$ (Figure $5 \mathrm{~b}$ ). Up until $3 \mathrm{~d}$ of hydration, portlandite formed in the blend containing $20 \%$ CSA cement. Simultaneously, some monocarboaluminate emerged in the PC and blends with $1 \%$ and $5 \%$ CSA cement. However, no monocarboaluminate formed in the CSA cement because anhydrite persisted throughout the hydration process.

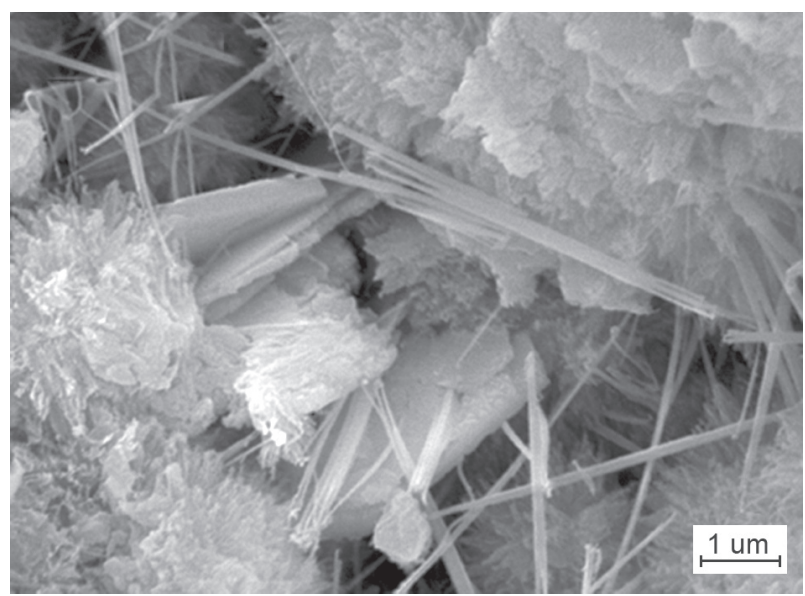

a) $\mathrm{P}-1$ day

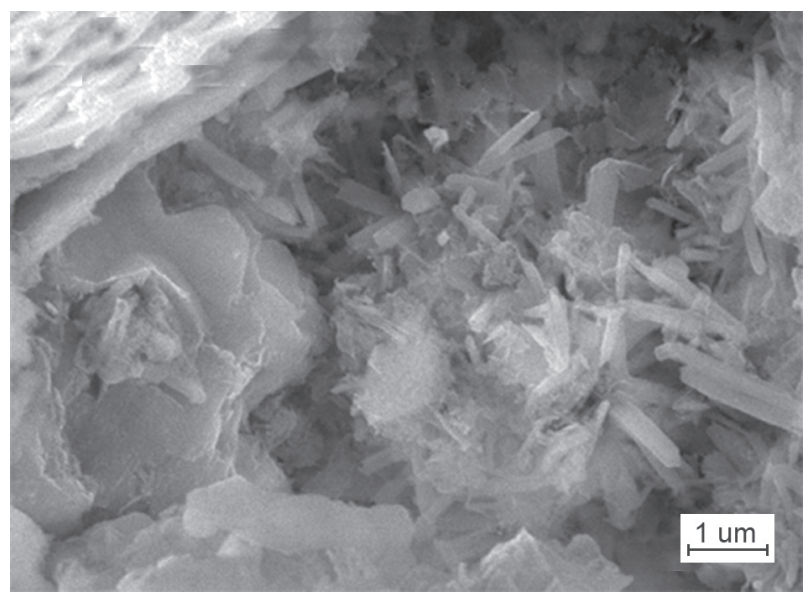

c) $20 \%-1$ day
Morphologies of

the hydration products

The morphology of ettringite was changed by the addition of the CSA cement. Figure 5a shows that ettringite existed as a thin and long elongated needle in the PC hydrated for $1 \mathrm{~d}$. However, its morphology became relatively thick and short when the CSA cement was added to the PC to generate the blended cements (Figures 6b, c, d). The morphology of ettringite in the blend pasture containing $20 \%$ CSA cement was similar to that in the pure CSA cement paste at $1 \mathrm{~d}$, in which it seemed to be covered by $\mathrm{AH}_{3}$ gel. In addition, portlandite was difficult to identify in the blend paste containing $20 \%$ CSA cement, whereas some was detected in both the PC and the blend with $5 \%$ CSA cement.

\section{Pore size distribution}

To investigate the effect of the CSA cement dosage on the pore structure of the PC, the pore size distributions of all pastes were determined (Figure 7). At an early hydration age ( $1 \mathrm{~d})$, a small amount of CSA cement decreased the pore size of the PC. The pore sizes were mainly distributed between $0.3 \mu \mathrm{m}$ and $2 \mu \mathrm{m}$ in the PC

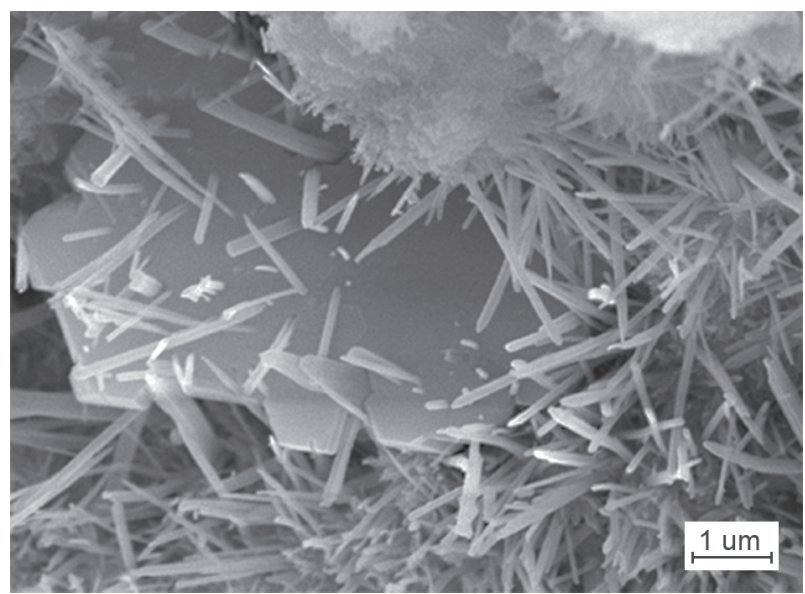

b) $5 \%-1$ day

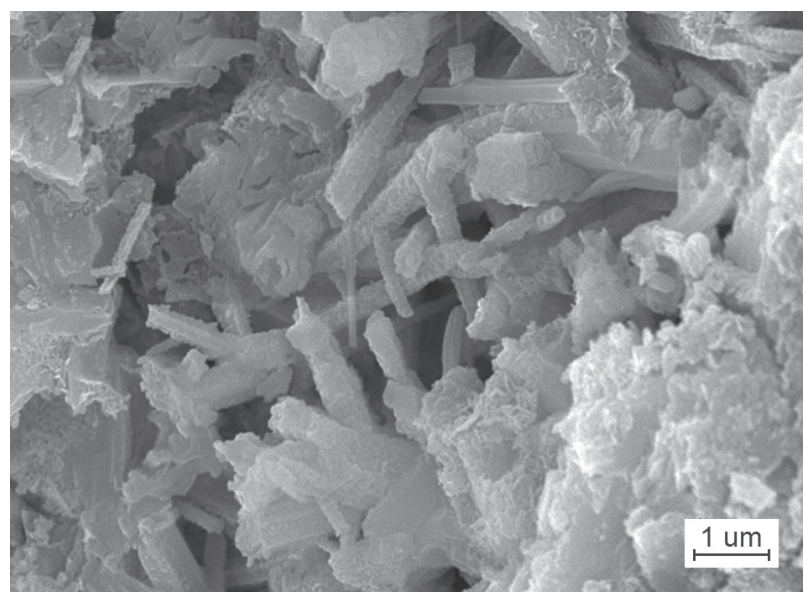

d) S - 1 day

Figure 6. The SEM images of the different cements hydrated for 1 day. 
paste and were reduced in the blends pastes with the $1 \%$ and $5 \%$ CSA cement. However, the cumulative pore volumes hardly changed in the blended pastes with $1 \%$ and $5 \% \mathrm{CSA}$ cement relative to that of the PC paste (Table 3). Compared with the PC paste, the addition of a greater amount of CSA cement $(20 \%)$ did not change the pore size. However, $20 \%$ CSA significantly increased the pore volume in the $0.3-2 \mu \mathrm{m}$ range. Consequently, the porosity of the blended paste with $20 \%$ CSA cement was higher than that of the PC paste (Table 4). Although $20 \%$ CSA cement accelerated the formation of ettringite in the blend paste at this age, it delayed the hydration of alite and hindered the formation of portlandite. Indeed, in the CSA cement paste, the pore size was very small because of the formation of large amounts of ettringite.

As hydration progressed, the pore sizes of all samples decreased. After 3 days of hydration, the pore size distributions of the blended pastes were similar to that of the PC paste, and the pore sizes were mainly distributed between $0.01 \mu \mathrm{m}$ and $1 \mu \mathrm{m}$. A small amount of CSA cement increased the pore volumes in the $0.05-0.1 \mu \mathrm{m}$ range, and a higher CSA cement content significantly enhanced the pore volumes in the $0.05-0.2 \mu \mathrm{m}$ range. The blended pastes exhibited higher porosities than the PC paste. The pore volumes in the range of $0.1 \mu \mathrm{m}$ to $1 \mu \mathrm{m}$ were substantially lower in the CSA cement paste, which decreased its porosity (Table 4).

At the late hydration age ( $28 \mathrm{~d})$, small amounts of CSA cement had no effects on the pore size distribution. Pores were distributed from $0.03 \mu \mathrm{m}$ to $0.1 \mu \mathrm{m}$ for all pastes, except for the blended paste with $20 \%$ CSA cement, which exhibited relatively large pore sizes. Additionally, the pore volumes in the $0.03-0.1 \mu \mathrm{m}$ range were enhanced in the blended and CSA cement pastes.

Table 3. ICSD collection codes and references for all phases used in the Rietveld quantitative phase analysis.

\begin{tabular}{lcc}
\hline Phase & ICSD code & Ref \\
\hline $\mathrm{C}_{3} \mathrm{~S}$ & 81100 & {$[16]$} \\
$\mathrm{C}_{2} \mathrm{~S}$ & 81096 & {$[17]$} \\
$\mathrm{C}_{3} \mathrm{~A}$ & 151369 & {$[18]$} \\
$\mathrm{C}_{4} \mathrm{AF}$ & 9197 & {$[19]$} \\
$\mathrm{C}_{4} \mathrm{~A}_{3} \$(\mathrm{O})$ & 237892 & {$[20]$} \\
$\mathrm{C}_{4} \mathrm{~A}_{3} \$(\mathrm{C})$ & 9560 & {$[21]$} \\
$\mathrm{CaSO}_{4}$ & 15876 & {$[22]$} \\
$\mathrm{C}_{12} \mathrm{~A}_{7}$ & 6287 & {$[23]$} \\
Dolomite & 10404 & {$[24]$} \\
Perovskite & 38212 & {$[25]$} \\
Calcite & 18165 & {$[26]$} \\
\hline
\end{tabular}

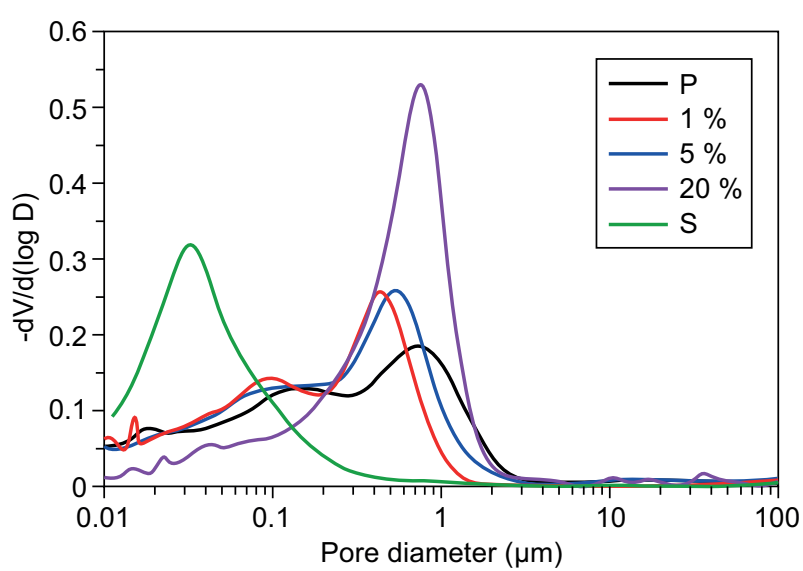

a) 1 day

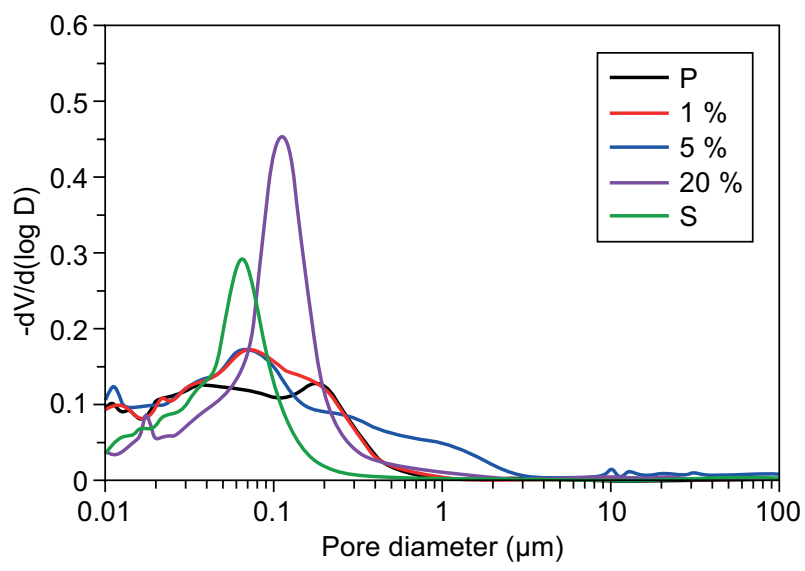

b) 3 days

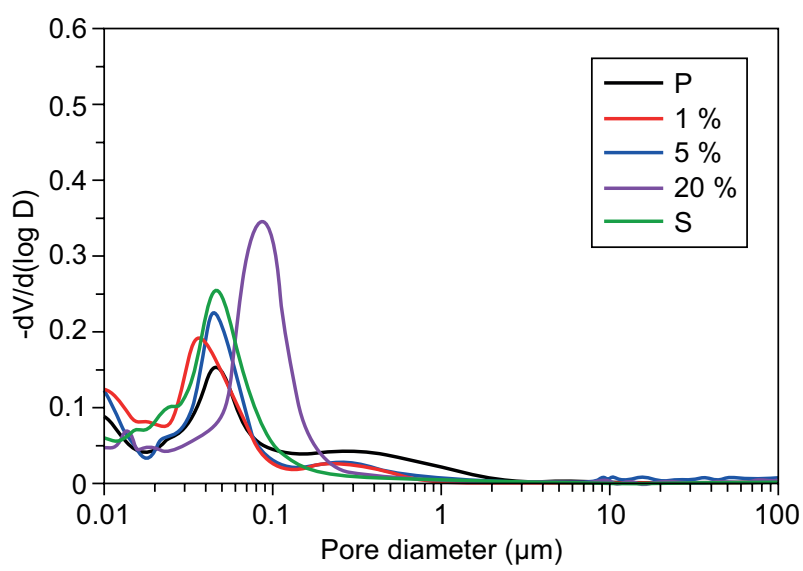

c) 28 days

Figure 7. Pore size distributions of the cements hydrated for 1 day, 3 days, and 28 days.

Table 4. Total porosity of cements hydrated for 1 day, 3 days and 28 days.

\begin{tabular}{lclclc}
\hline Samples & Total porosity $(\%)$ & Samples & Total porosity $(\%)$ & Samples & Total porosity $(\%)$ \\
\hline $\mathrm{P}-1$ day & 41.1 & $\mathrm{P}-3$ days & 26.7 & $\mathrm{P}-28$ days & 18.7 \\
$1 \%-1$ day & 39.3 & $1 \%-3$ days & 32.5 & $1 \%-28$ days & 23.7 \\
$5 \%-1$ day & 40.7 & $5 \%-3$ days & 35.4 & $5 \%-28$ days & 22.8 \\
$20 \%-1$ day & 47.2 & $20 \%-3$ days & 36.9 & $20 \%-28$ days & 27.2 \\
S - 1 day & 32.8 & $\mathrm{~S}-3$ days & 24.5 & $\mathrm{~S}-28$ days & 21.6 \\
\hline
\end{tabular}




\section{CONCLUSION}

- The setting times and compressive strengths depended on the dosage of the CSA cement. The addition of the CSA cement to the PC substantially shortened the setting times, and the setting time of the blend with $20 \%$ CSA cement approached that of the CSA cement. The compressive strengths of the blended mortar with less than $10 \%$ CSA cement decreased slightly at every hydration age relative to those of the PC mortars. The addition of a large amount of CSA (20\%) significantly lowered the compressive strengths at the early ages ( $1 \mathrm{~d}$ and $3 \mathrm{~d}$ ). However, the strong, negative effect of the CSA cement was reduced at late hydration ages.

- A small amount of CSA cement did not affect the hydration kinetics of the PC. The renewed hydration of $\mathrm{C}_{3} \mathrm{~A}$ was delayed in the blend containing $5 \% \mathrm{CSA}$ cement. However, when the dosage of CSA cement was increased to $20 \%$ by weight of the PC, the hydration kinetics changed substantially relative to that of the PC. The hydration of alite was seriously delayed. The second formation of ettringite was advanced and enhanced within $3 \mathrm{~h}$ of hydration of the blend with $20 \%$ CSA cement compared to that of the pure CSA cement.

- At the early hydration ages, the formation of ettringite accelerated as the dosage of the CSA cement increased. Additionally, the blend with $20 \%$ CSA cement contained higher contents of ettringite at $1 \mathrm{~h}$ than the pure CSA cement. However, the formation of portlandite was delayed by the addition of $20 \%$ CSA cement, which led to larger pore sizes and higher porosity relative to those of the other hydrated samples. In addition, the addition of the CSA cement significantly affected the morphology of ettringite.

\section{Acknowledgements}

The authors are grateful for the financial support of the National Key $R \& D$ Programme of China (No. 2017YFB0309902), the National Natural Science Foundation of China (51772146), the Key University Science Research Project of Jiangsu Province (NO. 17KJA430008), the state key laboratory of green building materials, Jiangsu National Synergetic Innovation Centre for Advanced Materials (SICAM), the National Building Materials Industry Technology Innovation Programme (2015- $\left.M_{3}-2\right)$ and a project funded by the Priority Academic Programme Development of Jiangsu Higher Education Institutions (PAPD). The support by the facilities of the Modern Analysis and Testing Centre at Nanjing TECH University, where the detailed microstructural analyses were performed, are also acknowledged.

\section{REFERENCES}

1. Sharp J. H., Lawrence C. D., Yang R. (1999): Calcium sulphoaluminate cements - low-energy cements, special cements or what. Advances in Cement Research, 11(1), 3-13. doi: 10.1680/adcr.1999.11.1.3

2. Glasser F. P., Zhang L. (2001): High-performance cement matrices based on calcium sulphoaluminate-belite compositions. Cement and Concrete Research, 31(12), 1881-1886. doi: 10.1016/S0008-8846(01)00649-4

3. Chen I. A., Hargis C. W., Juenger M. C. G. (2012): Understanding expansion in calcium sulfoaluminate-belite cements. Cement and Concrete Research, 42(1), 51-60. doi: 10.1016/j.cemconres.2011.07.010

4. Zhang L., Su M. Z., Wang Y. M. (1999): Development of the use of sulfo-and ferroaluminate cements in China. Advances in cement research, 11(1), 15-21. doi: 10.1680/ adcr.1999.11.1.15

5. Coumes C. C. D., Courtois S., Peysson S., Ambroise J., Pera, J. (2009): Calcium sulfoaluminate cement blended with OPC: A potential binder to encapsulate low-level radioactive slurries of complex chemistry. Cement and Concrete Research, 39, 740-747. doi: 10.1016/j.cemconres.2009.05.016

6. Pe'ra J., Ambroise J. (2004): New applications of calcium sulfoaluminate cement. Cement and Concrete Research, 34, 671-676. doi: 10.1016/j.cemconres.2003.10.019

7. Chaunsali P., Mondal P. (2015): Influence of Calcium Sulfoaluminate (CSA) Cement Content on Expansion and Hydration Behavior of Various Ordinary Portland CementCSA Blends. Journal of the American Ceramic Society, 98(8), 2617-2624. doi: 10.1111/jace. 13645

8. Pelletier L., Winnefeld F., Lothenbach B. (2010): The ternary system Portland cement-calcium sulphoaluminate clinker-anhydrite: Hydration mechanism and mortar properties. Cement and Concrete Composites, 32(7), 497-507. doi: 10.1016/j.cemconcomp.2010.03.010

9. Le Saoût G., Lothenbach B., Hori A., Higuchi T., Winnefeld F. (2013): Hydration of Portland cement with additions of calcium sulfoaluminates. Cement and Concrete Research, 43, 81-94. doi: 10.1016/j.cemconres.2012.10.011

10. Trauchessec R., Mechling J.-M., Lecomte A., Roux A., Le Rolland B. (2015): Hydration of ordinary Portland cement and calcium sulfoaluminate cement blends. Cement and Concrete Composites, 56, 106-114. doi: 10.1016/j.cemconcomp.2014.11.005

11. Lothenbach B., Le Saout G., Gallucci E., Scrivener K. (2008): Influence of limestone on the hydration of Portland cements. Cement and Concrete Research, 38(6), 848-860. doi: 10.1016/j.cemconres.2008.01.002

12. Ma S., Shen X., Gong X., Zhong B. (2006): Influence of $\mathrm{CuO}$ on the formation and coexistence of $3 \mathrm{CaO} \cdot \mathrm{SiO}_{2}$ and $3 \mathrm{CaO} \cdot 3 \mathrm{Al}_{2} \mathrm{O}_{3} \cdot \mathrm{CaSO}_{4}$ minerals. Cement and Concrete Research, 2006, 36 (9):1784-1787. doi: 10.1016/j.cemconres.2006.05.030

13. Ma S., Snellings R., Li X., Shen X., Scrivener K. L. (2013): Alite-ye'elimite cement: Synthesis and mineralogical analysis. Cement and Concrete Research, 45(1), 15-20. doi: 10.1016/j.cemconres.2012.10.020

14. Larson A.C., Dreele R.B.V., Larson A.C., Dreele R.B.V. (2000). General Structure Analysis System (GSAS). Report La-UR-86-748. Los Alamos National Laboratory, New Mexico, USA. 
15. Toby B. H. (2001): EXPGUI, a graphical user interface for GSAS. Journal of Applied Crystallography, 34(2), 210-213. doi:10.1107/S0021889801002242

16. Mumme W G. (1995): Crystal structure of tricalcium silicate from a Portland cement clinker and its application to quantitative XRD analysis. Neues Jahrbuch fur Mineralogie Monatshefte, 4, 145-145.

17. Mumme W. G, Hill R. J, Bushnell-Wye G, Segnit E.R. (1995): Rietveld crystal structure refinements, crystal chemistry and calculated powder diffraction data for the polymorphs of dicalcium silicate and related phases. Neues Jahrbuch fur Mineralogie Abhandlungen, 169(1),35-68.

18. Mondal P., Jeffery J. W. (1975): The crystal structure of tricalcium aluminate, $\mathrm{Ca}_{3} \mathrm{Al}_{2} \mathrm{O}_{6}$. Acta Crystallographica Section B, 31(3), 689-697. doi: 10.1107/S0567740875003639

19. Pedersen B. F., Semmingsen D. (1982): Neutron diffraction refinement of the structure of gypsum, $\mathrm{CaSO}_{4} \cdot 2 \mathrm{H}_{2} \mathrm{O}$. Acta Crystallographica, 38(4), 1074-1077. doi: 10.1107/ S0567740882004993

20. Cuesta A, De la Torre A. G, Losilla E. R, Peterson V. K, Rejmak P, Ayuela A, Aranda M. A. (2013): Structure, atomistic simulations, and phase transition of stoichiometric yeelimite. Chemistry of Materials, 25(9), 1680-1687. doi: $10.1021 / \mathrm{cm} 400129 \mathrm{z}$

21. Calos N. J, Kennard C. H. L, Whittaker A. K, Davis R. L. (1995): Structure of calcium aluminate sulfate $\mathrm{Ca}_{4} \mathrm{Al}_{6} \mathrm{O}_{16} \$$. Journal of Solid State Chemistry, 119(1), 1-7. doi: 10.1016/ 0022-4596(95)80002-7

22. Cheng G. C. H, Zussman J. (1963): The crystal structure of anhydrite $\left(\mathrm{CaSO}_{4}\right)$. Acta Crystallographica, 16(8), 767-769. doi: 10.1107/S0365110X63001997

23. Novák J, Coufová P. (1968): Zur defektstruktur des $\mathrm{Al}_{2} \mathrm{O}_{3}$. Collection of Czechoslovak Chemical Communications, 33(3), 656-663. :

24. Drits V. A, McCarty D. K, Sakharov B, Milliken K. L. (2005): New insight into structural and compositional variability in some ancient excess-Ca dolomite. The $\mathrm{Ca}$ nadian Mineralogist, 43 (4), 1255-1290. doi: 10.2113/ gscanmin.43.4.1255

25. Yamanaka T,. Hirai N., Komatsu Y. (2002): Structure change of $\mathrm{Ca} 1-\mathrm{xSrxTiO}$. perovskite with composition and pressure. American Mineralogist, 87(8-9), 1183-1189. doi: 10.2138/am-2002-8-917
26. Chessin H., Hamilton W.C., Post B. (1965): Position and thermal parameters of oxygen atoms in calcite. Acta Crystallographica, 18(4): 689-693. doi: 10.1107/S0365110 X65001585

27. Qian L. I. (2007): Research of Composite Cement on Silicate and Sulphoaluminate. Journal of Liaoning University (Natural Sciences Edition), 2, 017.

28. Hesse C., Goetz-Neunhoeffer F., Neubauer J. (2011): A new approach in quantitative in-situ XRD of cement pastes: Correlation of heat flow curves with early hydration reactions. Cement and Concrete Research, 41(1), 123-128. doi: 10.1016/j.cemconres.2010.09.014

29. Jansen D., Goetz-Neunhoeffer F., Lothenbach B., Neubauer J. (2012) The early hydration of Ordinary Portland Cement (OPC): An approach comparing measured heat flow with calculated heat flow from QXRD. Cement and Concrete Research, 42(1), 134-138. doi: 10.1016/j.cemconres.2011. 09.001

30. Jansen D., Goetz-Neunhoeffer F., Stabler C., Neubauer J. (2011): A remastered external standard method applied to the quantification of early OPC hydration. Cement and Concrete Research, 41(6), 602-608. doi: 10.1016/j. cemconres.2011.03.004

31. Scrivener K. L., Juilland P., Monteiro P. J. M. (2015): Advances in understanding hydration of Portland cement. Cement and Concrete Research, 78, 38-56. doi: 10.1016/j. cemconres.2015.05.025

32. Rahhal V., Talero R. (2005): Early hydration of Portland cement with crystalline mineral additions. Cement and Concrete Research, 35(7), 1285-1291. doi: 10.1016/j. cemconres.2004.12.001

33. He Z., Yang H. M., Liu M. Y. (2014): Hydration mechanism of sulphoaluminate cement. Journal of Wuhan University of Technology-Mater. Sci. Ed., 29(1), 70-74. doi: 10.1007/ s11595-014-0869-8

34. Minard H., Garrault S., Regnaud L., Nonat A., (2007): Mechanisms and parameters controlling the tricalcium aluminate reactivity in the presence of gypsum, Cement and Concrete Research, 37, 1418-1426. doi: 10.1016/j. cemconres.2007.06.001

35. Allevi S., Marchi M., Scotti F., Bertini S., Cosentino C. (2016): Hydration of calcium sulphoaluminate clinker with additions of different calcium sulphate sources, Materials and Structures, 49, 453-466. doi: 10.1617/s11527-0140510-5 